\title{
FABRICATION and CHARACTERIZATION OF GaSb BASED THERMOPHOTOVOLTAIC CELLS USING Zn DIFFUSION FROM A DOPED SPIN-ON GLASS SOURCE
}

\author{
S. Dakshinamurthy, G. Charache, M. Freeman
}

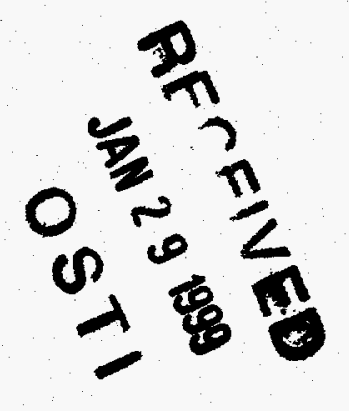

June 1998

DLSTRIBUTION OF THIS DOCUMENT IS UHHLATED

\section{MASTER}

\section{NOTICE}

This report was prepared as an account of work sponsored by the United States Government. Neither the United States, nor the United States Department of Energy, nor any of their employees, nor any of their contractors, subcontractors, or their employees, makes any warranty, express or implied, or assumes any legal liability or responsibility for the accuracy, completeness or usefulness of any information, apparatus, product or process disclosed, or represents that its use would not infringe privately owned rights. 


\section{DISCLAIMER}

This report was prepared as an account of work sponsored by an agency of the United States Government. Neither the United States Governmeat nor any agency thereof, nor any of their employees, makes any warranty, express or implied, or assumes any legal liability or responsibility for the accuracy, completeness, or usefulness of any information, apparatus, product, or process disclosed, or represents that its use would not infringe privately owned rights. Reference herein to any specific commercial product, process, or service by trade name, trademark, inanufac. turer. or otherwise does not necessarily constitute or imply its endorsement, recommendation, or favoring by the United States Government or any agency thereof. The views and opinions of authors expressed herein do not necessarily state or reflect those of the United States Govermment or any agency thereof. 


\section{DISCLAIMER}

Portions of this document may be illegible in electronic image products. Images are produced from the best available original document. 
Fabrication and Characterization of GaSb based Thermophotovoltaic cells using Zn Diffusion from a doped spin-on glass source

S. Dakshinamurthy, S. Shetty, I. Bhat, C. Hitchcock and R. Gutmann ECSE Department \& Center for Integrated Electronics,

- - Rensselaer Polytechnic Institute, Troy, NY 12180-3590

and

G. Charache and M. Freeman

Lockheed Martin Corp., Schenectady, NY 12180-1072.

\begin{abstract}
The GaInSb material system is attractive for application in thermophotovoltaic (TPV) cells since its band gap can be tuned to match the radiation of the emitter. At present, most of the TPV cells are fabricated using epitaxial layers and hence are expensive. To reduce the cost, $\mathrm{Zn}$ diffusion using elemental vapors in a semi-closed diffusion system is being pursued by several laboratories. In this paper, we present studies carried out on $\mathrm{Zn}$ diffusion into n-type (Te-doped) GaSb substrates in an open tube diffusion furnace. The dopant precursor was a $2000 \AA$ thick, zinc doped spin-on glass. The diffusion was carried out at temperatures ranging from 550 to $600{ }^{\circ} \mathrm{C}$, for times from 1 to 10 hours.
\end{abstract}

The diffused layers were characterized by Hall measurements using step-andrepeat etching by anodic oxidation, secondary ion mass spectrometry (SIMS) measurements and TPV device fabrication. For diffusion carried out at $600{ }^{\circ} \mathrm{C}$, the junction depth was $0.3 \mu \mathrm{m}$, and the hole concentration near the surface was $5 \times 10^{19} / \mathrm{cm}^{3}$. The external quantum efficiency, measured without any anti-reflection coating, of the TPV cells fabricated using mesa-etching had a maximum value of $38 \%$. Masked diffusion was also carried out by opening windows in a $\mathrm{Si}_{3} \mathrm{~N}_{4}$ coated, $\mathrm{GaSb}$ wafer. TPV cells fabricated on these structures had similar quantum efficiency, but lower dark current. 


\section{Introduction}

Zinc is commonly used as a p-type dopant in several III-V semiconductors, including GaSb. Diffusion of zinc in these materials is characterized by high surface concentration and sharp diffusion profiles, that are ideal for TPV devices. In addition, diffusion of zinc into $\mathrm{GaSb}$ and GaInSb material systems presents an inexpensive method of making p-on-n TPV devices compared to the more typical epitaxially grown structures.

$\mathrm{Zn}$ diffusion has been achieved in GaSb by different techniques that include elemental $\mathrm{Zn}$ diffusion in both a sealed ampoule and pseudo closed-box systems and by using Zn-doped spin-on glasses [1]-[9]. The doping profiles obtained in these studies were very sharp and non-Fickian. This has led to a theory of the diffusion mechanism based on an interstitial-substitutional model [3]. In this theory, the substitutional $\mathrm{Zn}$ atoms are relatively immobile and diffusion occurs mainly through interstitial $\mathrm{Zn}$ atoms that diffuse until they move into substitutional sites. The diffusion of the interstitial $\mathrm{Zn}$ atoms is modeled by an error-function profile, where the diffusion constant (D) is proportional to the ratio of the $\mathrm{Zn}$ and $\mathrm{Ga}$-vacancy $\left(\mathrm{V}_{\mathrm{Ga}}\right)$ concentration;

$$
D \propto \frac{[Z n]^{n}}{\left[V_{G a}\right]_{0}}
$$

where $\mathrm{n}$ is $\sim 2$ and $\left[\mathrm{V}_{\mathrm{Ga}}\right]_{0}$ is the Ga vacancy concentration at the surface. The in-diffusion of Ga-site vacancies (due to out-diffusion of $\mathrm{Ga}$ atoms) is expected to be faster than that of the $\mathrm{Zn}$ atoms. Hence, equation 1 predicts that diffusivity reduces with diffusion time (and hence distance) which results in sharp diffusion profiles. From the above diffusion mechanism it is also expected that a large number of vacancies are created that diffuse faster than the $\mathrm{Zn}$ and hence are present just under the junction.

Of the above mentioned methods of $\mathrm{Zn}$ diffusion, spin-on glass diffusion is attractive because it can be done in an open tube furnace without the need for sealing or 
evacuation of ampoules. In addition, prevention of surface decomposition and attainment of repeatable diffusions are accomplished without a controlled overpressure of $\mathrm{Sb}$ as required in solid source diffusion performed in the ampoules and pseudo-closed box systems. On the other hand, it has been shown that the spin-on glass not only acts as a diffusion source but also helps prevent the thermal decomposition of the GaSb surface [8]. In the present study, $\mathrm{Zn}$ diffusion was performed on $\mathrm{n}$ and $\mathrm{p}$ type $\mathrm{GaSb}$ using $\mathrm{Zn}$ doped spin-on glasses.

\section{Experimental details}

\section{Diffusion}

Two types of GaSb (100) substrates were used in the study: (a) Te-doped, n-type substrates with a carrier concentration of $5 \times 10^{17} / \mathrm{cm}^{3}$, supplied by MCP Wafer Technology and (b) high resistivity, undoped p-type substrates with a carrier concentration of $\sim 8 \times 10^{14} / \mathrm{cm}^{3}$ at $77 \mathrm{~K}$, supplied by Firebird Semiconductor. The high resistivitiy of the p-type substrates facilitated Hall measurements to study the diffusion. It was assumed that the diffusion in n-type substrates would be identical to the p-type substrates due to the low concentration of Te compared to the expected concentration of $\mathrm{Zn}[3]$.

Substrate cleaning was performed by initial degreasing in a hot bath of xylene, followed by rinses in acetone and methanol. The wafer was then dipped in $\mathrm{HCl}$ for $1 \mathrm{~min}$. to remove surface oxide and given a quick etch in Bromine-methanol ( $\sim 1 \%$ solution). Following this, the sample was again rinsed thoroughly in methanol and blown dry in filtered $\mathrm{N}_{2}$ [10]. A $\mathrm{Zn}$ doped spin-on glass solution (obtained from Emulsitone $\mathrm{Co}$.) was spun on at a spin speed of $3500 \mathrm{rpm}$ for 20 secs. The sample was then baked at $100^{\circ} \mathrm{C}$ for about $20 \mathrm{~min}$. in order to drive off the solvent and form the glass layer. The spin-on glass was usually about $0.2-0.25 \mu \mathrm{m}$ thick at the end of the baking step. These films are essentially similar to pyrolytic $\mathrm{SiO}_{2}$, but with a $\mathrm{Zn}$ concentration of $\sim 10^{20} / \mathrm{cm}^{3}$. However, their dielectric strength and etching resistance in $\mathrm{HF}$ are inferior to that of thermal $\mathrm{SiO}_{2}$ layers. The wafers were then placed in a fused silica boat and introduced slowly into an open-tube furnace, in a neutral ambient of ultra high purity $\mathrm{Ar}$ or $\mathrm{N}_{2}$ with a low $\mathrm{H}_{2} \mathrm{O}$ 
content. It was ensured that the temperature gradient experienced by the sample was always $<50{ }^{\circ} \mathrm{C} / \mathrm{min}$., in order to prevent cracking of the film due to thermal shock. The duration and temperature of the diffusion step were varied. At the end of the diffusion step, the sample was removed from the diffusion tube, taking care to ensure that the ramp-down rate was again $<50{ }^{\circ} \mathrm{C} / \mathrm{min}$. The spin-on glass was stripped from the $\mathrm{GaSb}$ surface in dilute HF solution (1:10).

\section{Hall Measurements}

The p-type substrates used for the diffusion were characterized by making Van der Pauw structures. Ohmic contacts were formed on the four corners of the square sample using indium dots annealed under a nitrogen flow at $250^{\circ} \mathrm{C}$. Hall measurement was performed at $77 \mathrm{~K}$ by immersing the sample in liquid nitrogen. As the thickness and profile of the diffused layer were unknown, only the sheet resistance and average mobility could be determined from the Hall measurements. The contribution of the substrate was removed by using previously measured Hall data of the substrate. The doping profile was determined by etching the top surface of the wafers in steps of $500 \AA$ and conducting Hall measurements after each etching step [11]. Anodic oxidation was used for this purpose. Anodic oxide of $\mathrm{GaSb}$ was grown in an aqueous glycol water (AGW) electrolyte, consisting of 1:2 mixtures of a $3 \%$ solution of tartaric acid in deionized water and ethylene glycol. $\mathrm{NH}_{4} \mathrm{OH}$ was added to adjust the $\mathrm{pH}$ value to be $\sim 4$. The sample to be anodized was placed at the anode and a graphite bar was used as the cathode. The oxidation was performed using a constant current source, with a current density $\sim 1 \mathrm{~mA} / \mathrm{cm}^{2}$. The thickness of the anodic oxide is directly proportional to the voltage built up across the cell, and hence this voltage (V) can be used as a measure of the oxide thickness. After the desired voltage (and hence, the desired thickness) had been reached, the current source was turned off and the sample removed from the electrolyte. The surface was thoroughly rinsed in DI water and methanol. The thickness of the oxide $T_{o x}$ was then measured using a spectroscopic ellipsometer (The refractive index at $\lambda=$ $6328 \AA$ was determined to be 2.0 ), followed by a strip in $\mathrm{HCl}$. Step height measurements on GaSb surfaces protected from the electrolyte, gave a dT ox $/ \mathrm{dV}$ of $32 \AA / \mathrm{V}$, confirming the correlation between anode voltage and the etch depth. 
The sheet resistance $\rho_{\mathrm{si}}$ and mobility $\mu_{i}$ were measured using the Van der Pauw method, at each step ( $i$ ) of the profiling process until the sheet resistance had reached a constant value, close to the typical substrate sheet resistance at $77 \mathrm{~K}$ of $\sim 500-1000$ $\Omega /$ square. The procedure for obtaining the carrier concentration and mobility of the $i$ th layer is outlined in Appendix A. The carrier concentration obtained was also compared with SIMS data obtained on these samples.

\section{TPV device fabrication}

TPV devices including diodes with a circular cross-section of varying area, as well as large, optically sensitive cells with metal grids and bus bars were fabricated on the p-n junctions made on Te doped n-type substrates. $200 \AA$ of Sn followed by $2000 \AA$ of Au were deposited and annealed at $250 \mathrm{C}$ for $1 \mathrm{~min}$. to form the back-contacts to the $\mathrm{n}$ layer. $2000 \AA$ of $\mathrm{Au}$ were used for the front contact to the p-type layer. A lift-off photolithography process was used to fabricate the front contacts. The devices were isolated by mesa-etching beyond the junction. Mesa-etching was performed using a $\mathrm{NaK}$ tartarate based etchant $\left(12 \mathrm{gm}\right.$. $\mathrm{NaK}$ Tartarate $+9 \mathrm{ml} \mathrm{H}_{2} \mathrm{O}_{2}+33 \mathrm{ml} \mathrm{HCl}$ in a $500 \mathrm{ml}$ solution in $\mathrm{DI} \mathrm{H}_{2} \mathrm{O}$ ) with an estimated etch rate of $1000 \AA / \min [12,15]$.

The fabricated TPV devices were characterized using a four probe Kelvin measurement setup to measure the dark and illuminated I-V characteristics. In addition, spectral response (or external quantum efficiency) was measured using a monochromator with the bias on the cell $\sim 0 \mathrm{~V}$ (short circuit condition). The dark I-V data were then used to extract the saturation current density, ideality factor, series- and shunt-resistance of the cell using a curve-fitting program. Details about the measurement setup and device models used can be found in [13].

\section{Results}

Diffusions were performed for temperatures between $550{ }^{\circ} \mathrm{C}$ to $600{ }^{\circ} \mathrm{C}$. These wafers were examined after stripping the spin-on glass after diffusion and displayed 
specular surfaces indicating that the surfaces had undergone little decomposition. The Hall mobility in the diffused layers were lower than that of the bulk p-type substrates, which can be explained by increased impurity scattering in the highly doped layer. It was also found that diffusion at $550{ }^{\circ} \mathrm{C}$ did not yield samples with low enough sheet resistance to indicate that any substantial diffusion had taken place.

The sheet resistance and mobility obtained from the differential Hall profiling performed on two samples in which $\mathrm{Zn}$ diffusion was performed at $600{ }^{\circ} \mathrm{C}$ for $1 \mathrm{hr}$ and 4 hrs are shown in Figs. 1 and 2, respectively. The carrier concentration and mobility profile versus depth were extracted from this data and are shown in Fig. 3. A significant amount of zinc (mid $-10^{19} / \mathrm{cm}^{3}$ ) has diffused into the GaSb layer. The junction depth obtained after diffusion for 4 hours is about twice that of the diffusion carried out for 1 hour. The carrier concentration profile exhibits a sharp drop as expected from previous work on $\mathrm{Zn}$ diffusion. The junction depths obtained by SIMS for these diffusions agree closely with the anodic oxidation profiling results. However, the carrier concentrations obtained from the two methods do not match very well. This may be because anodic profiling is not a very accurate method. The SIMS data also show a significant concentration of oxygen and silicon diffusing into the samples to depths of about $1000 \AA$, possibly from the glass.

The junction depth of about $0.3 \mu \mathrm{m}$ in 1 hour yields an average diffusivity of the order of $10^{-13} \mathrm{~cm}^{2} / \mathrm{s}$ at $600^{\circ} \mathrm{C}$. This is about one order of magnitude less than those predicted from diffusivities reported in an earlier study on sealed tube diffusion [3]. This is due to the lower surface concentration of $\mathrm{Zn}$ in the spin-on-glass diffusion. Hence, the concentration dependent diffusion constant is reduced which results in lower junction depths.

Mesa-etched diodes were fabricated by $\mathrm{Zn}$ diffusion into $\mathrm{Te}$ doped n-type substrates for $1 \mathrm{hr}$ at $600{ }^{\circ} \mathrm{C}$. These diodes exhibited saturation current densities around $10^{-3} \mathrm{~A} / \mathrm{cm}^{2}$. A typical I-V curve for one of the diodes is shown in Fig. 4. Diodes fabricated using $\mathrm{Zn}$ diffusion performed for $4 \mathrm{hrs}$ at $600{ }^{\circ} \mathrm{C}$ also exhibited similar 
saturation current densities. The saturation current density $J_{0}$, ideality factor $\eta$, series resistance $R_{s}$ and shunt resistance $R_{s h}$ were extracted using a curve-fitting program [13]. An example of the curve fit to the forward J-V characteristics of the diode mentioned above is shown in Fig. 5. We see that $\mathrm{J}_{0}$ is about $7 \times 10^{-4} \mathrm{Acm}^{-2}$. The ideality factor, $\eta$, lies in the range 1.1-1.3, indicating that diffusion current appears to be the dominant mechanism, as is expected for low band-gap materials such as GaSb. Also, $\mathrm{J}_{0}$ does not vary much for diffusions done for 1 hour and 4 hours, since the top p-type layer is much more heavily doped than the n-type substrate. Similar results were obtained when $\mathrm{Zn}$ diffusion was carried out at $600{ }^{\circ} \mathrm{C}$ for $80 \mathrm{~min}$. and $320 \mathrm{~min}$. on n-type GaSb showing the repeatability of the diffusion process. In general, it was observed that the ideality factors for the smaller devices (with dia. $<650 \mu \mathrm{m}$ ) were lower $(\eta \sim 1.1-1.3)$ compared to those for the $0.2 \mathrm{~cm}^{2}$ devices $(\eta \sim 1.6-1.8)$. It is probable that the larger devices may contain localized areas of high defect concentration, where generation-recombination processes can dominate. Also, the problem of surface inversion due to Fermi-level pinning in $\mathrm{n}$ type $\mathrm{GaSb}$ [14] gives rise to a large amount of surface leakage current. The various current conduction mechanisms occurring in these devices are yet to be fully understood.

These devices were also optically characterized by measuring the external quantum efficiency (Q.E.) as described earlier. The external quantum efficiency is shown in Fig. 6. The maximum value is around $38-40 \%$. Taking the reflectance of the front surface into account, the maximum achievable external Q.E. of GaSb devices is around $64 \%$. The spectral response of devices with shallow emitters is determined by the characteristics of the base (the n-type substrate, in our case). Hence, the less than perfect Q.E. in these devices can be attributed to a less than optimum diffusion length in the n-type substrate.

Finally, to study the effect of junction passivation on the device characteristics, a $1000 \AA$ thick layer of silicon nitride was deposited using a plasma enhanced chemical vapor deposition process at $300{ }^{\circ} \mathrm{C}$ on the n-type substrates before diffusion. Diffusion was then performed using spin-on glass through windows opened in the nitride diffusion 
mask. Hence, the $p-n$ junction was buried under the nitride mask due to lateral diffusion. Therefore, the devices on the wafer did not need to be mesa-etched for isolation. These devices showed improved reverse I-V characteristics and lower shunt leakage currents (at low forward biases) as shown in Fig. 7. However there was no change in the forward I-V characteristics at higher biases suggesting that the diffusion related saturation current does not change. Hence, this method helps to passivate the junction and reduce the dark current of the TPV device and seems to be better than making TPV devices by mesa-etching, which exposes the junction. The Q.E.s obtained by the two processes, however, are similar as shown in Fig. 6 since junction passivation does not affect the Q.E.

Studies were also conducted to reduce the surface concentration of $\mathrm{Zn}$ in the diffused layer by diluting the $\mathrm{Zn}$-Silica film by a factor of 10 with undoped silica film (also supplied by Emulsitone Co.). However, no appreciable changes in the sheet resistance of the high resistivity p-type material after the diffusion were observed, suggesting that no diffusion took place in this case. The absence of diffusion was attributed to the fact that the diffusion constant was drastically reduced due to the lower surface concentration of zinc. This suggests that there may be a limitation on the lowest surface concentration one can get by this diffusion method.

\section{Conclusions}

We have demonstrated the capability of $\mathrm{Zn}$-doped spin-on-glass to serve as an effective p-type diffusion source for $\mathrm{GaSb}$. Diodes fabricated on $\mathrm{Zn}$-diffused $\mathrm{GaSb}$ samples exhibited $\mathrm{J}_{0} \sim 10^{-3} \mathrm{~A} / \mathrm{cm}^{2}$, with ideality factors between 1.1-1.6 for most devices. Repeated diffusions gave identical device characteristics, showing that the process was highly repeatable. We have also demonstrated the use of the process in making TPV devices with good spectral response. 


\section{$V$ References}

1. B. I. Boltaks and A. Gutorov, J. Phys-Solid St., 1, (1960), p. 930.

2. R. Chin and H. D. Law, J. Electrochem. Soc, 128 (1981), p 227.

3. G. J. Conibeer, A. F. W. Willoughby, C. M. Hardingham and V. K. M. Sharma, J. Electon. Mater., 25, (1996), p. 1108.

4. V. S. Sundaram and P. E. Grenbaum, J. Appl.Phys., 73, 1993, p. 3787.

5. A. W. Bett, S. Keser, G. Stollwerck and O. V. Sulima, Proceedings of the Third NREL Conference on Thermophotovoltaic Generation of Electricity, May 1997, AIP Proceedings, 401, (1997) p. 41.

6. A. Joullie, F. De.Anda, P. Salsac and M. Mebarki, Rev. Phys. Appl., 19, (1984), p 223. 7. L. M. Fraas, G. R. Girard, J. E. Avery, B. Arau, V. S. Sundaram and A. G. Thompson, J. Appl. Phys., 66, (1989), p 3866.

8. C. Heinz, J. Electrochem. Soc., 135, (1988), p 250.

9. C. Heinz, Solid-State Electronics, 36, p.1685.

10. M. Kodama, J. Hasegawa and M. Kimata, J. Electrochem. Soc., 136, (1985), p. 659.

11. D. K. Schroder, "Semiconductor material and device characterization", WileyInterscience, (1990).

12. F. W. O. Da Silva, M. Silga, C. Raisin and L. Lassabatere, J. Vac. Sci. Technol. B, 8, (1990), p. 75.

13. C. Hitchcock, R. Gutmann, J. Borrego, H. Ehsani, I. Bhat, M. Freeman and G. Charache, Proceedings of the Third NREL Conference on Thermophotovoltaic Generation of Electricity, May 1997, AIP Proceedings, 401, p. 89.

14. W. E. Spicer, P.W. Chye, P. R. Skeath, C. Y. Su and I. Lindau, J. Vac. Sci and Technol., 16, (1979), p. 1422.

15. J.C. Buglass, T. D. Mclean and D. G. Parker, J. Electrochem. Soc., 133, p. 2565. 


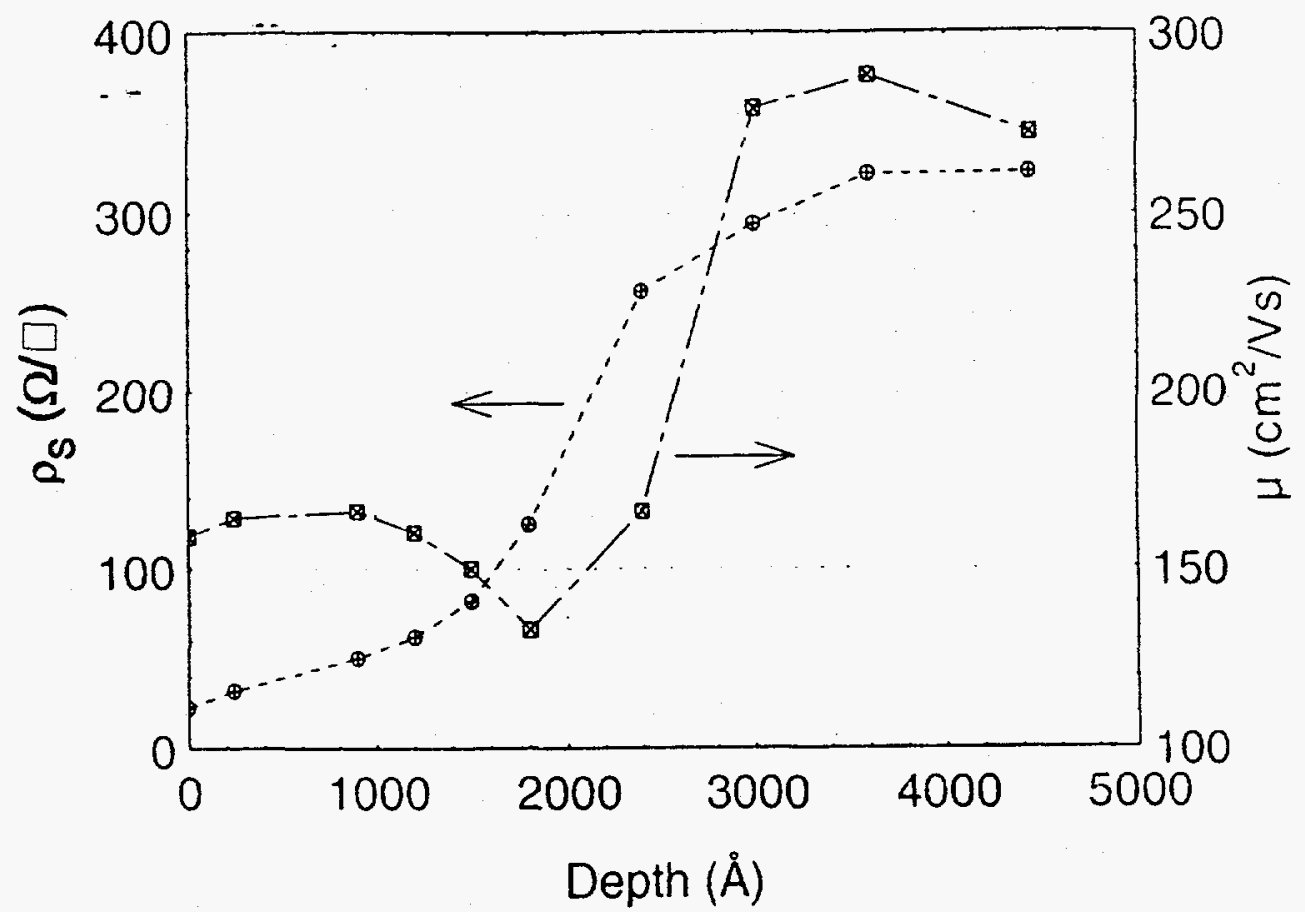

Figure 1. Raw Hall data measured at $77 \mathrm{~K}$ during anodic profiling of a $\mathrm{Zn}$-diffused layer. Diffusion was carried out at $600^{\circ} \mathrm{C}$ for 1 hour. 


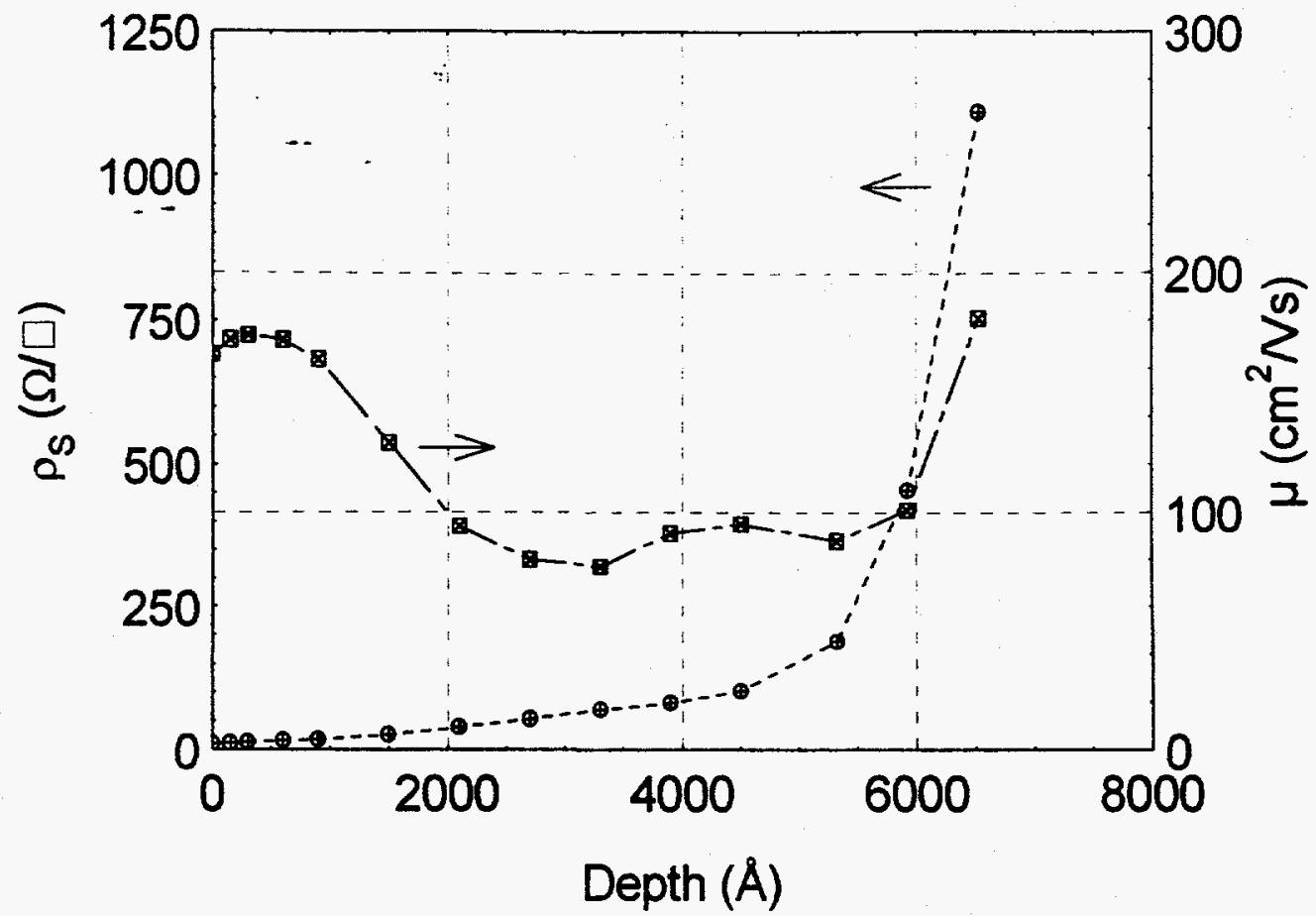

Figure 2. Raw Hall data measured at $77 \mathrm{~K}$ during anodic profiling of a $\mathrm{Zn}$-diffused layer. Diffusion was carried out at $600^{\circ} \mathrm{C}$ for 4 hours. 


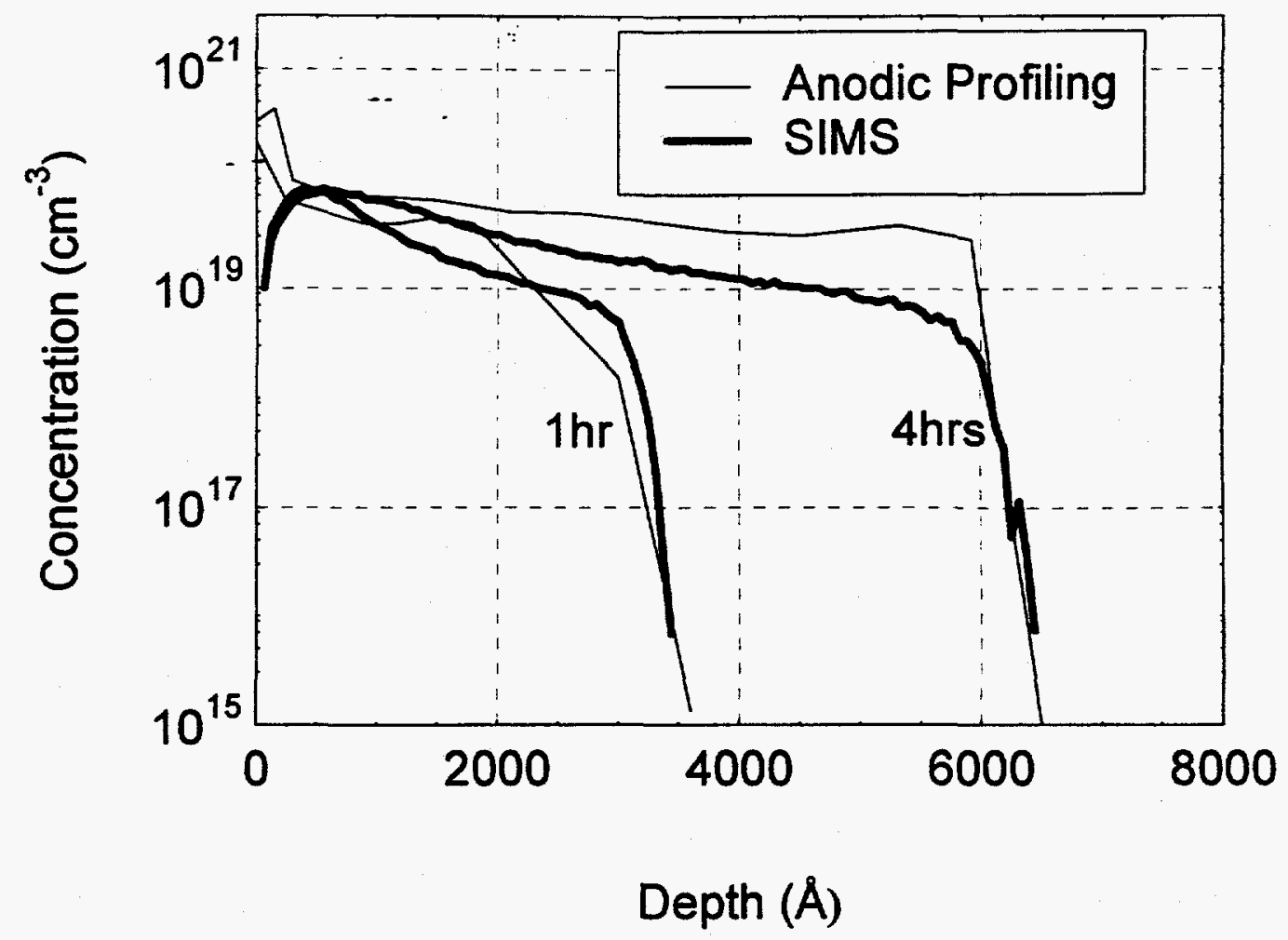

Figure 3. Carrier concentration profile at $77 \mathrm{~K}$ determined by anodic profiling and $\mathrm{Zn}$ profile determined by SIMS, on two $\mathrm{Zn}$-diffused samples. The diffusion times are marked in the figure. 


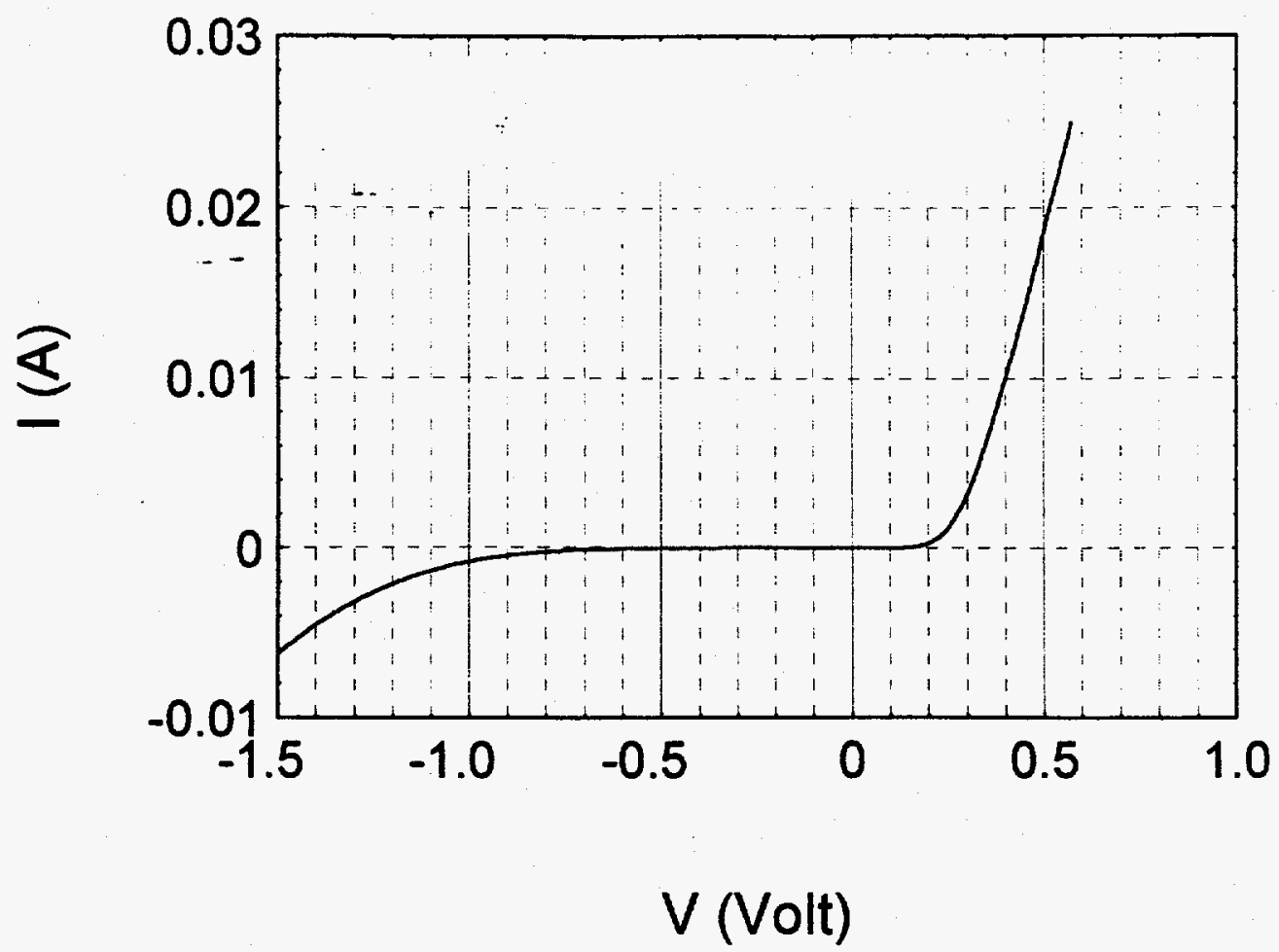

Figure 4. I-V characteristics of a GaSb p-n junction diode ( $300 \mu$ m diameter) made by $\mathrm{Zn}$ diffusion at $600^{\circ} \mathrm{C}$ for 1 hour. 


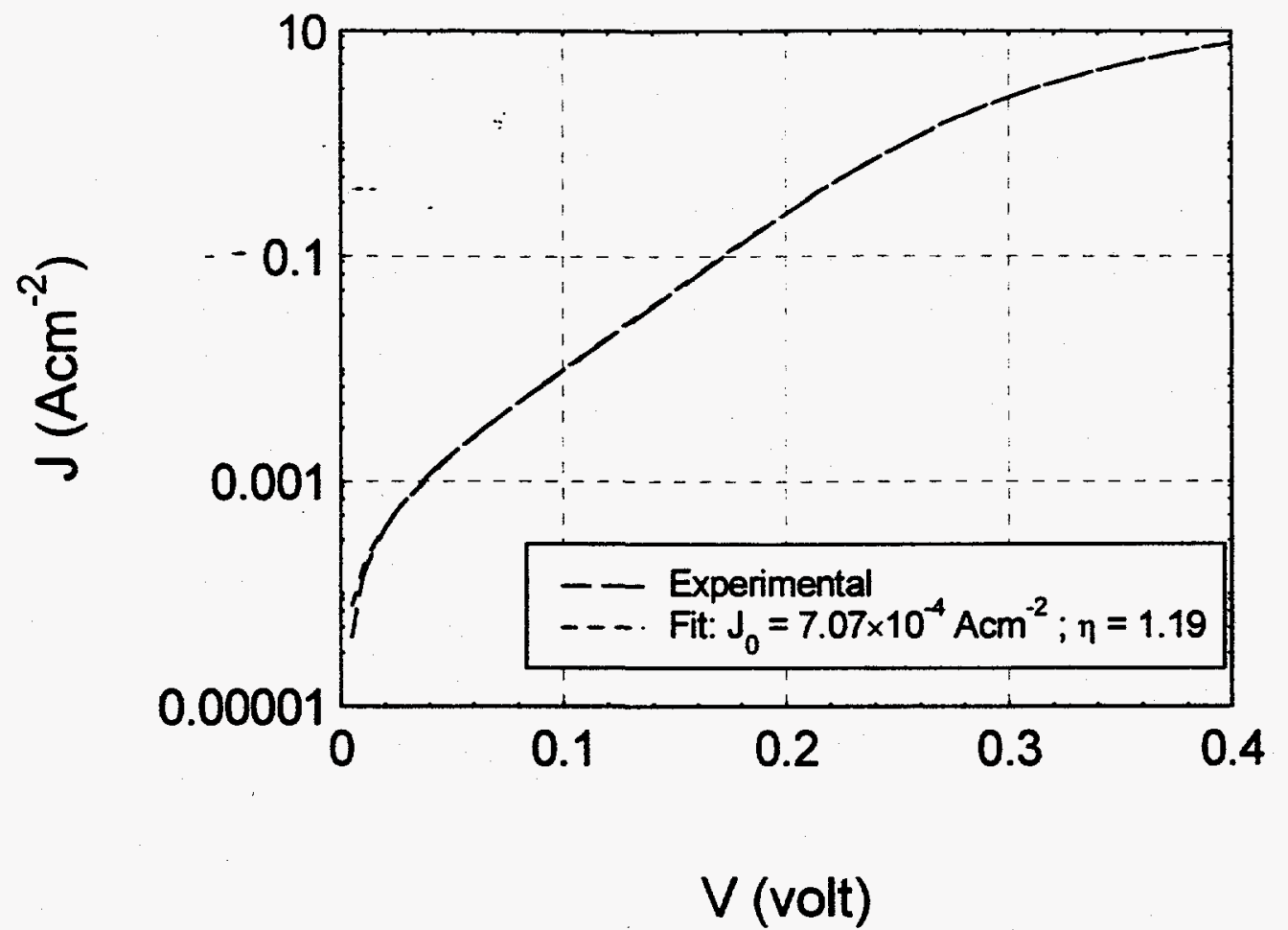

Figure 5. Forward J-V characteristics of a $\mathrm{GaSb}$ p-n junction diode made by $\mathrm{Zn}$ diffusion at $600{ }^{\circ} \mathrm{C}$ for 1 hour. The agreement between the experimental and simulated curves is excellent. 


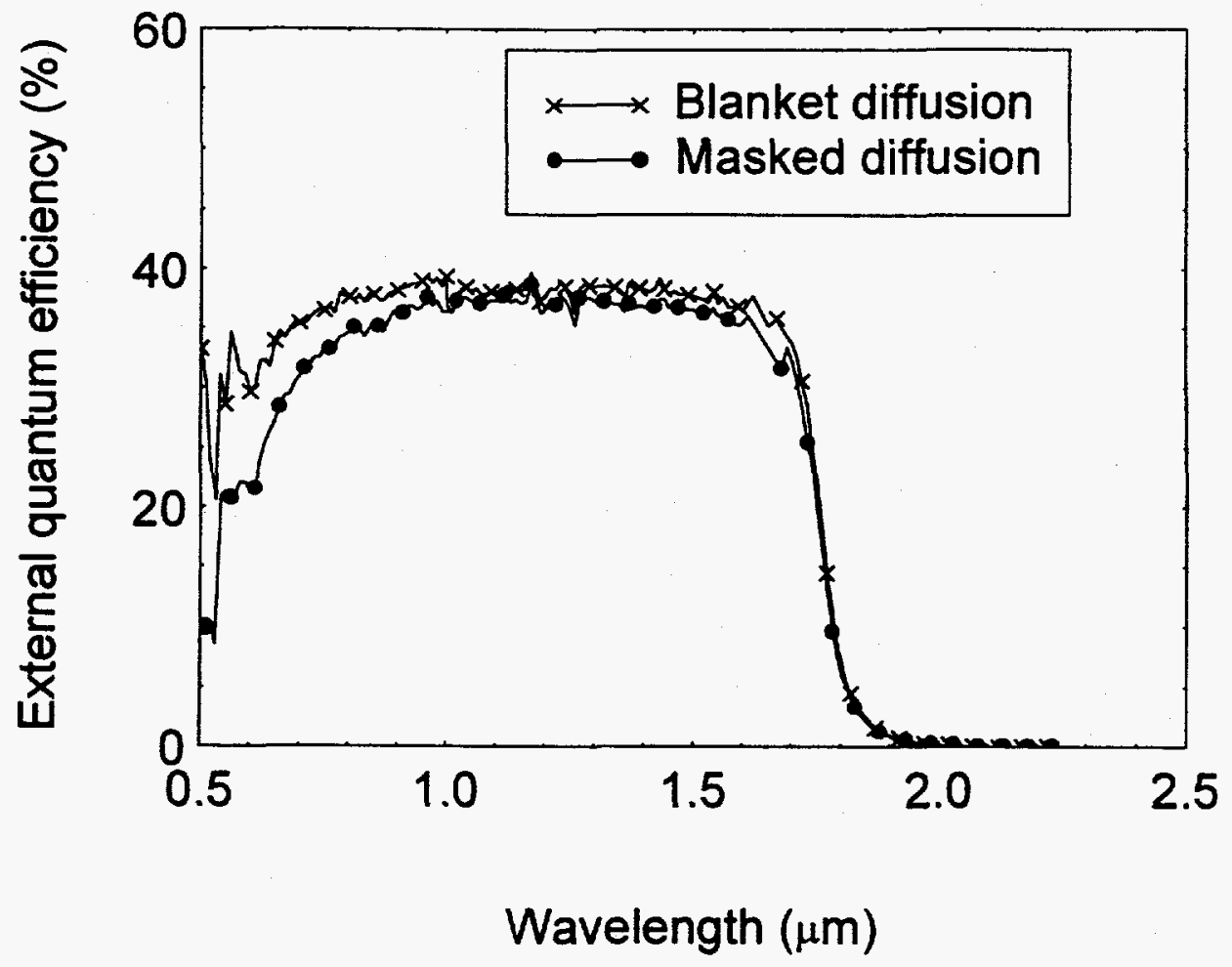

Figure 6. External quantum efficiency of $\mathrm{GaSb} \mathrm{p}-\mathrm{n}$ junction diodes made by $\mathrm{Zn}$ diffusion at $600{ }^{\circ} \mathrm{C}$ for 4 hours, with and without a silicon nitride diffusion mask. 


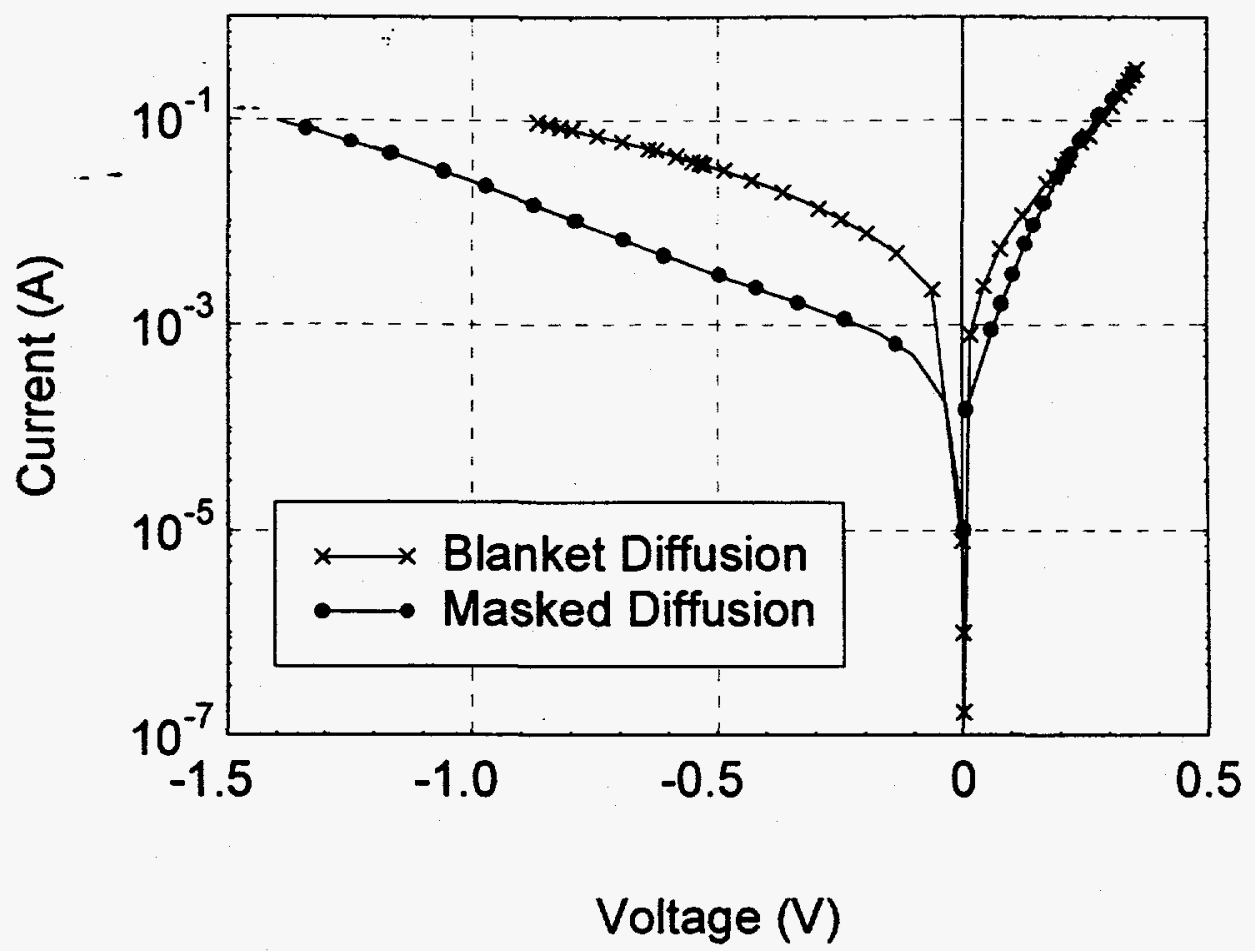

Figure 7. I-V characteristics of GaSb p-n junction diodes made by $\mathrm{Zn}$ diffusion at $600{ }^{\circ} \mathrm{C}$ for 4 hours, with and without a silicon nitride diffusion mask. 


\section{Appendix A}

The sheet resistance $\left(\rho_{s i}\right)$ of the diffused layer after etching the $i$ th layer is given by [11],

$$
\rho_{s_{i}}=\left[q \int_{x_{i}}^{t} p(x) \mu(x) d x\right]^{-1}
$$

Here, $x$ is the coordinate measured from the surface into the diffused layer, $x_{i}$ is the coordinate of the surface after etching the $i$ th layer, $q$ is the electronic charge, $p(x)$ and $\mu(x)$ are the carrier concentration and mobility respectively of the diffused layer at any point $x$. If $\mu_{i}$ is the average mobility of the diffused layer after etching the $i$ th layer, the mobility of the $i$ th layer that was etched can be found from,

$$
\mu\left(x_{i}\right) \cong \frac{\left(\frac{\mu_{i}}{\rho_{s_{i}}}\right)-\left(\frac{\mu_{i+1}}{\rho_{s_{i+1}}}\right)}{\left(\frac{1}{\rho_{s_{i}}}\right)-\left(\frac{1}{\rho_{s_{t+1}}}\right)}
$$

and the carrier concentration of the $i$ th layer that was etched is given by

$$
p\left(x_{i}\right) \cong \frac{\left(\frac{1}{\rho_{s_{i}}}\right)-\left(\frac{1}{\rho_{s_{i+1}}}\right)}{q \mu\left(x_{i}\right) \Delta x_{i}}
$$

where $\Delta x_{i}$ is the thickness of the $i$ th layer etched. 